УДК 681.5.01: 629.52.7

DOI: 10.31471/2415-3184-2019-1(19)-69-77

О. А. Маиков ${ }^{\text {, В. М. Триснюк', Ю. В. Мамчур }}{ }^{2}$, С. В. Жукаускас ${ }^{2}$, С. А. Нігородова ${ }^{2}$, А. В. Курило

${ }^{1}$ Державна екологічна академія післядипломної освіти та управління, м. Київ

${ }^{2}$ Інститут телекомунікацій $і$ глобального інформачійного простору НАН України, м. Київ

\title{
НОВИЙ ПІДХІД ДО СИНТЕЗУ ВІДНОВЛЮЮЧОГО КЕРУВАННЯ ДЛЯ ДИСТАНЦІЙНО ПІЛОТОВАНИХ ЛІТАЛЬНИХ АПАРАТІВ ЕКОЛОГІЧНОГО МОНІТОРИНГУ
}

У зв'язку з ускладненням об'єктів керування з'явилося багато задач, в яких потрібно спочатку розрахувати бажаний закон зміни керованого процесу (програмний рух), а потім побудувати закон керування, що забезпечує точне або наближене здійснення цього процесу в умовах можливого виникнення нештатних ситуацій.

Запропоновано новий підхід до синтезу відновлюючего керування для дистанційно пілотованих літальних апаратів екологічного моніторингу. Обгрунтована можливості застосування концепції зворотних задач динаміки для синтезу систем керування дистанційно пілотованих літальних апаратів для здійснення стабілізації на заданій траєкторії руху в стохастичній постановці. Основна задача полягає в побудові системи керування програмним рухом, що забезпечує здійснення програмної траєкторії із заданою точністю за наявності різного роду збурень.

Запропоновано здійснювати розробку алгоритмів синтезу відновлюючого керування для дистанційно пілотованих літальних апаратів з використанням концепції зворотних задач динаміки. Ця концепція передбачає формалізацію задачі здійснення заданої траєкторії руху при виникненні нештатної ситуації шляхом стабілізації програмного руху (термінальне керування, адаптивне стеження). Оцінено ефективність алгоритму керування дистанційно пілотованим літальним апаратом на основі вирішення зворотної задачі динаміки для стохастичної багатовимірної автоматичної системи на модельному прикладі.

Методику синтезу відновлюючого керування з використанням концепції зворотних задач динаміки доцільне застосовувати при побудові систем керування дистанційно пілотованих літальних апаратів. Запропонований підхід може застосовуватися як до одновимірних так i багатовимірних систем автоматичного керування складними динамічними об'єктами.

Ключові слова: зворотна задача динаміки, перехідний процес, програмна траєкторія руху, система керування, час перехідного процесу, якість керування, дистанційно пілотований літальний апарат.

Постановка проблеми. До останнього часу в теорії автоматичного керування в основному було розглянуто завдання, в яких потрібно було підтримувати вихідний сигнал (режим) об'єкта керування на одному і тому ж постійному рівні (завдання стабілізації), або забезпечити відстежування невідомої заздалегідь змінної задавального впливу (завдання стеження). Проте у зв'язку з ускладненням об'єктів керування виникло багато завдань, в яких потрібно спочатку розрахувати бажаний закон зміни керованого процесу (програмний рух), а потім побудувати закон керування, що забезпечує точне або наближене здійснення цього процесу в умовах можливого виникнення нештатних ситуацій. Такі завдання виникають при управлінні дистанційно пілотованими літальними апаратами екологічного моніторингу.

Складність вирішення цих завдань на практиці [12-28] визначається такими трьома факторами:

1. Реальний рух у початковий момент може суттєво відрізнятися від програмного. Це пов'язано з наявними початковими збуреннями, виникненням нештатної ситуації.

2. Дійсні значення параметрів об’єкта керування через параметричні збурення відрізняються від їхніх оцінок, використовуваних при побудові рівняння.

3. Наявні діючі збурення. 
Тому, якщо система керування не здатна парирувати вплив перелічених факторів, автоматично пристосовуючись до існуючих зовнішніх умов i внутрішніх - спричинених відмовами бортового обладнання, то реальний рух може суттєво відрізнятися від програмного. Мета керування - рух за програмною траєкторією в цих умовах - може бути не досягнута. Отже, постає завдання побудови системи керування програмним рухом, що забезпечує здійснення програмної траєкторії із заданою точністю за наявності різного роду збурень.

Застосування класичних методів керування до побудови систем керування програмним рухом стикається 3 труднощами. Ці труднощі пов'язані з тим, що при виникненні нештатних ситуацій ряд існуючих властивостей керованого об'єкта і умови його функціонування заздалегідь не відомі. Дослідження показують, що застосування законів керування на основі розв'язання зворотної задачі динаміки дозволяє знизити рівень випадкових складових у координатах стану. Такі закони керування бувають ефективні при побудові функціонально-стійких автоматичних систем.

Аналіз останніх досліджень та публікацій. Викладено методику синтезу функціональностійких систем керування програмним рухом, що базується на ідеях методу, розробленого Петровим Б. М., Поповим Е. П., Крутько П. Д., а також методу, розробленого Тимофєєвим А. В.

У роботах Барбашина Е. А. розглянуто питання наближення здійснення руху динамічного об'єкта за заданою траєкторією[1]. Дослідженню побудови алгоритмів керування як зворотної задачі динаміки присвятили свої праці Петров Б. Н., Крутько П. Д., Попов Є. П. [2-5]. Методи розв'язання зворотних задач запропоновано Галіулліним А. С. [6]. Синтезу алгоритмів керування польотом літального апарата на основі розв'язання зворотних задач динаміки присвячені праці Артюшина Л. М., Панова В. І., Шамова Г. В. [7-11].

Метою статті $\epsilon$ обгрунтування можливості застосування концепції зворотних задач динаміки для синтезу систем керування дистанційно пілотованих літальних апаратів для здійснення стабілізації на заданій траєкторії руху в стохастичній постановці.

Виклад основного матеріалу дослідження. Розглянемо алгоритм керування дистанційно пілотованим літальним апаратом на оперативно програмованій траєкторії в стохастичній постановці.

Представимо рівняння руху досліджуваного об'єкта у вигляді:

$$
\dot{X}(t)=A X(t)+B U(t)+G \xi(t),
$$

де $U(t)-m$-вимірний вектор керувальних функцій; $\xi(t)-r$-вимірний вектор випадкових збурень.

Вважаємо матриці $A, B, G$ заданими. Щодо вектор-функції припустимо, що вона має такі властивості:

$$
M[\xi(t)]=0, M\left[\xi(t) \xi^{T}(t-\tau]=P_{\xi}(t) \delta(t-\tau) .\right.
$$

Матриця $\mathrm{P}_{\xi}$ розмірності $(r, r)$ характеризує інтенсивність випадкових збурень і вважається відомою. Рівняння вимірника має вигляд:

$$
Z(t)=H X(t)+\eta(t)
$$

де $\eta=\left(\eta_{1} \ldots \eta_{k}\right)^{T}-$ вектор випадкових похибок, що має такі властивості:

$$
M[\eta(t)]=0, M\left[\eta(t) \eta^{T}(t-\tau]=P \cdot_{\eta}(t) \delta(t-\tau) .\right.
$$

Матриця $P_{\eta}$ розмірності $(k, k)$ характеризує інтенсивність завади $\eta(t)$.

Вважаємо також, що процеси $\xi(t)$ і $\eta(t)$ статистично незалежні. Це припущення відповідає багатьом прикладним задачам.

Рівняння (1) розглядатимемо як модель збуреного руху. У такому разі задача керування полягає в тому, щоб утримувати систему в окрузі початку координат

$$
X(t) \rightarrow O_{(n)}
$$

Практично режим керування можна вважати збуреним, якщо значення математичне очікування $M[X(t)]$ суттєво перевищують прийнятий рівень випадкових складових координат вектора стану.

Для збуреного режиму закон керування слід синтезувати з умови здійснення призначеної траєкторії руху з точки $M[X(0)]$ у початок координат (розглядаються лінеаризовані рівняння). 
У незбуреному режимі закон керування має забезпечувати рух керованого об'єкта в можливо меншій окрузі початку координат.

Розглянемо ці режими. Закон керування рухом даної системи приймаємо у вигляді:

$$
\begin{aligned}
& U=C Z(t)=C H X(t)+C \eta(t), \\
& M[\eta(t)]=0, \\
& M\left[\eta(t) \eta^{T}(t)\right]=P_{\eta}(+) \delta(t-\tau) .
\end{aligned}
$$

Матриця параметрів $C=\left\{C_{i j}\right\}, i=\overline{1, m}, j=\overline{1, k}$ підлягає визначенню.

Для збуреного за математичним очікуванням $M[X(t)]$ режиму керування параметри $\left\{C_{i j}\right\}$ визначаються в результаті оптимізації детермінованої системи:

$$
\begin{aligned}
& \dot{M}[X(t)]=A M[X(t)]+B M[U(t)] ; \\
& M[U(t)]=C H M[X(t)] .
\end{aligned}
$$

Для незбуреного (за математичним очікуванням) режиму параметри закону керування визначаються з умови, щоб дисперсії координат стану були мінімальними в кожен момент часу .

Початковою, в цьому разі, є система стохастичних рівнянь:

$$
\begin{gathered}
\frac{d \stackrel{\circ}{X}(t)}{d t}=A \stackrel{\circ}{X}(t)+B \stackrel{\circ}{U}(t)+G \xi(t) ; \\
\stackrel{\circ}{U}(t)=C H \stackrel{\circ}{X}(t)+G \eta(t) .
\end{gathered}
$$

Тут

$$
\begin{gathered}
\stackrel{\circ}{X}(t)=X(t)-m_{X}(t), \\
\stackrel{\circ}{U}(t)=U(t)-m_{U}(t) .
\end{gathered}
$$

Матричне диференціальне рівняння для матриці других центральних моментів вектора стану:

$$
\begin{aligned}
& \stackrel{\circ}{D}(t)=A D(t)+D(t) A^{T}+B C H D(t)+ \\
& +D(t) H^{T} C^{T} B^{T}+B C P_{\eta} C^{T} B^{T}+G P_{\xi}(t) G^{T} .
\end{aligned}
$$

Для стохастичної системи (7), (8) мінімум дисперсії вихідних координат досягається в тому разі, якщо для кожного $t>0$ похідна $\stackrel{\circ}{D}(t, C)$ приймає екстремальне значення в просторі параметрів $C_{j}$. Це, у свою чергу, буває, якщо $C_{j}$ задовольняють систему рівнянь:

$$
\frac{\partial D(t, C)}{\partial C_{j}}=0, j=\overline{1, k} .
$$

Параметри, що задовольняють цю умову $\left|C_{1}^{\sigma} \ldots C_{k}^{\sigma}\right|=C_{\sigma}^{T}$, називатимемо оптимальними.

Оптимальні значення елементів матриці параметрів закону керування задовольняють умови

$$
\frac{d}{d t}\left[d_{i i}(t, C)\right]=\min _{C}\left[d_{i i}(t, C)\right], i=\overline{1, n}
$$

Щоб знайти необхідні розрахункові співвідношення для $C_{\sigma}$, слід виконати диференціювання $d_{i i}(t, C)$ за $C_{i j}$.

Диференціювання діагональних елементів матриці $D(t)$ зручно проводити, якщо ввести такі позначення: 


$$
\begin{aligned}
& B=\left[\begin{array}{c}
b_{1}^{T} \\
\vdots \\
b_{n}^{T}
\end{array}\right] ; C=\left[c_{1}, c_{2}, \ldots c_{k}\right], \\
& H=\left[\begin{array}{c}
h_{1}^{T} \\
\vdots \\
h_{k}^{T}
\end{array}\right] ; D=\left[d_{1}, d_{2}, \ldots d_{k}\right] .
\end{aligned}
$$

3 урахуванням введених позначень діагональні елементи матриці $D(t, C)$ можна диференціювати за векторами $C_{i}$, що дає систему векторних рівнянь:

$$
\frac{d}{d C i}\left(e_{i}^{T} D e_{i}\right)=0, i=\overline{1, k}
$$

де

$$
e_{1}=\left[\begin{array}{c}
1 \\
0 \\
\cdots \\
0
\end{array}\right], \cdots, e_{k}=\left[\begin{array}{c}
0 \\
0 \\
\cdots \\
1
\end{array}\right] .
$$

Вирішуючи рівняння (10) можна отримати

$$
B C_{\sigma} P_{\eta}(t)+D_{d}(t) \cdot H^{T}=0
$$

Матриця $D_{\sigma}(t)$, що входить до цього виразу, визначається з диференціального рівняння (9) при оптимальному значенні $C=C_{\sigma}$, яке дорівнює:

$$
\sigma_{0}(t)=-\left(B^{T} B\right)^{-1} B^{T} D_{\sigma}(t) H^{T} P_{\eta}^{-1}(t) .
$$

Очевидно, що для незбуреного (за математичним очікуванням) режиму керування параметри залежать від часу. Це зумовлено двома причинами. Одна 3 них полягає в тому, що інтенсивність $P_{\eta}(t)$ похибок вимірювання не постійна. Інша причина полягає в тому, що навіть при стаціонарному випадковому процесі $\eta(t)$ вектор $C_{\sigma}=C_{\sigma}(t)$, оскільки матриця $D_{\sigma}(t)$ других центральних моментів у перехідному процесі змінюється в часі.

Диференціальне рівняння для $D_{\sigma}(t)$ можна отримати із загального рівняння (9), якщо підставити в нього вираз (11) $C_{\sigma}(t)$

$$
\dot{D}_{\sigma}(t)=A D_{\sigma}(t)+D_{\sigma}(t) A^{T}=R Q_{\sigma}(t) R^{T}+G P_{\xi}(t) G^{T},
$$

де позначено

$$
\begin{gathered}
R=B\left(B^{T} B\right)^{-1} B^{T} ; Q_{\sigma}(t)=D_{\sigma}(t) H^{T} P_{\eta}^{-1}(t) H D_{\sigma}(t) ; \\
R=R^{T} ; Q_{\sigma}(t)=Q_{\sigma}^{T}(t) .
\end{gathered}
$$

Рішення $D_{\sigma}(t)$ матричного рівняння (12) використовується для обчислення $C_{\sigma}(t)$ за формулою (11). Як початкова умова $D_{\sigma}(0)$ для рівняння (12) може приймати деяке апріорне значення, виходячи 3 допустимого рівня шумів проектованої системи, тобто питання це вирішується з урахуванням особливостей проектованої системи і умов ії функціонування.

Проте, при виконанні обчислювальних процедур, можна як початкові умови прийняти $D_{\sigma}(0)=0$. 
Зазвичай у практиці приймають, що випадкова функція $\xi(t)$ стала, тобто $\sigma_{\xi}(t)=\mathrm{const}$, похибки вимірювання $\eta_{i}(t)$ також є сталими випадковими функціями $P_{n}=$ const . Стале значення $D_{\sigma}(\infty)=$ const , отже, згідно з (11) оптимальне значення $C_{\sigma}(\infty)=$ const .

Оцінимо ефективність алгоритму керування дистанційно пілотованим літальним апаратом на основі розв'язання зворотної задачі динаміки для стохастичної багатовимірної автоматичної системи на модельному прикладі.

Розглянемо систему:

$$
\dot{X}(t)=\left[\begin{array}{ccc}
0 & 1 & 0 \\
0 & 0 & 1 \\
-0,3 & -3 & -0,1
\end{array}\right] \cdot X(t)+\left[\begin{array}{lll}
2 & 1 & 4 \\
0 & 3 & 2 \\
1 & 0 & 1
\end{array}\right] \cdot U(t)+\left[\begin{array}{c}
1 \\
0 \\
1
\end{array}\right] \cdot \xi(t) .
$$

Рівняння вимірника має вигляд:

$$
Z(t)=\left[\begin{array}{lll}
1 & 0 & 0 \\
0 & 1 & 0
\end{array}\right] \cdot X(t)+\eta(t) .
$$

Характеристики випадкових функцій мають вигляд:

$$
\sigma_{\xi}^{2}=0,01 ; P_{\eta}=\left[\begin{array}{cc}
0,01 & 0 \\
0 & 0,01
\end{array}\right] .
$$

Для збуреного (за математичним очікуванням) режиму параметри закону керування визначені з умови наближення $X(t)$ до вектора стану $X(t)$ системи:

$$
\dot{Y}(t)=\left[\begin{array}{ccc}
0 & 1 & 0 \\
0 & 0 & 1 \\
-1 & -3 & -3
\end{array}\right] \cdot Y(t) .
$$

Як міра наближення $X(t) \rightarrow Y(t)$ прийнятий функціонал:

$$
\begin{gathered}
J(c)=\int_{0}^{T}[X(t, c)-Y(t)]^{T} V[X(t, c)-Y(t)] d t, \\
V=\left[\begin{array}{ccc}
100 & 0 & 0 \\
0 & 10 & 0 \\
0 & 0 & 1
\end{array}\right] .
\end{gathered}
$$

Оптимальні параметри для збуреного режиму дорівнюють:

$$
\left\{C_{i j}^{*}\right\}=\left[\begin{array}{cc}
0,386 & 6,308 \\
0,009 & 1,666 \\
-0,197 & -3,672
\end{array}\right]
$$

На рис. 1 наведені графіки, що характеризують зміну середньоквадратичних значень:

$$
\sigma_{i j}=\sqrt{\alpha_{i j}}
$$

координат стану $X_{i}$ для того випадку, коли закон керування $U(x)=C H X$. Аналізуючи наведені на рис. 1 залежності, можна зробити такі висновки:

1. Рівень випадкових складових у координаті стану дуже високий.

2. Параметри $C_{i j}$, знайдені для збуреного (за математичним очікуванням) режиму керування, не можна визнати оптимальними для незбуреного режиму. 
На рис. 2 наведені залежності середньоквадратичних значень $\sigma_{i j}^{\min }(t)$, які отримані для закону керування

$$
U(x)=C_{\sigma} Z,
$$

синтезованого з умови реалізації мінімальних дисперсій у кожен момент часу.

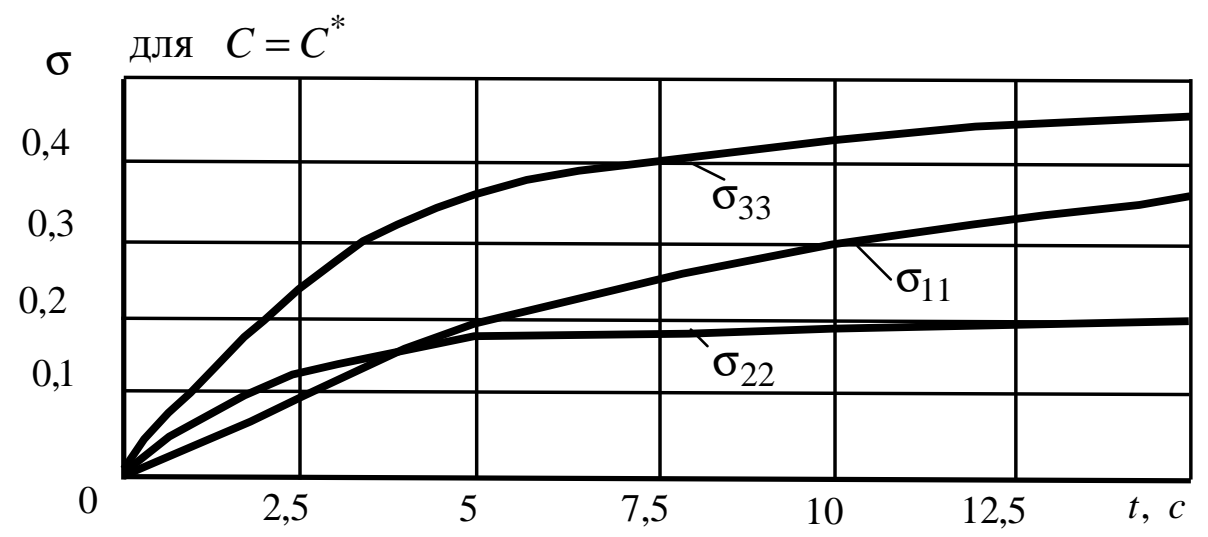

Рис. 1. Графік зміни середньоквадратичних значень $\sigma_{i j=\sqrt{\alpha_{i j}}}$

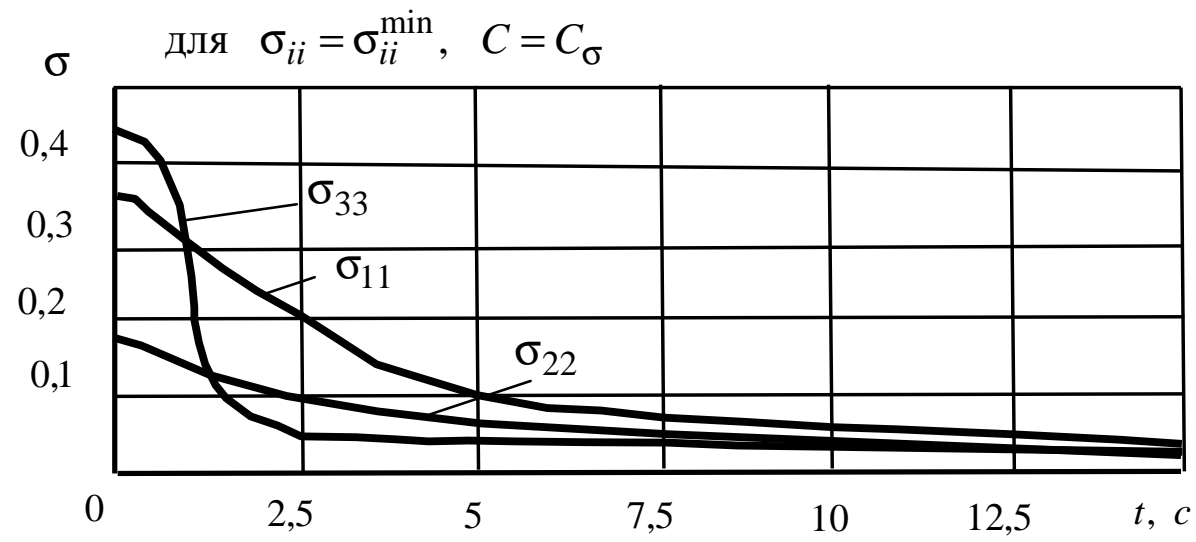

Рис. 2. Графік зміни середньоквадратичних значень для закону керування $\sigma_{i j}^{\min }(t)$

Ці дані відповідають тому разі, коли початкове значення $D_{\sigma}(0)$ у рівнянні (12) прийняте рівним сталому значенню матриці $D(t)$, отриманої для системи 3 параметрами $C=C^{*}$. Оптимальні значення параметрів $C_{i j}^{\sigma}$ змінюються в процесі керування, тобто $є$ функцією часу (рис. 3).

У сталому режимі:

$$
\left\{C_{i j}^{\sigma}(\infty)\right\}=\left[\begin{array}{cc}
0,845 & -0,116 \\
0,557 & -0,077 \\
-0,786 & 0,199
\end{array}\right] .
$$

Отже, на основі сформульованого поняття функціональної стійкості і запропонованих методів синтезується відновлювальне керування, що забезпечує виведення динамічної системи 3 нештатних ситуацій.

Подальшим етапом досліджень планується моделювання і оцінювання ефективності розроблених алгоритмів для різних умов застосування дистанційно пілотованих літальних апаратів. 


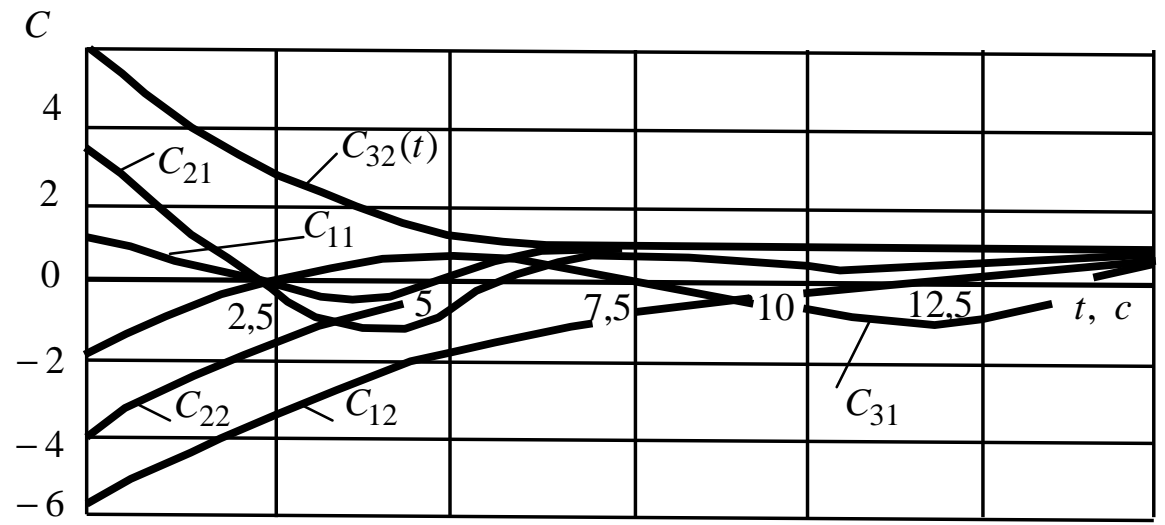

Рис. 3. Графік оптимальних значень параметрів $C_{i j}^{\sigma}$ у процесі керування

Висновки та перспективи подальших досліджень. Розроблення алгоритмів синтезу відновлювального керування для дистанційно пілотованих літальних апаратів передбачається здійснювати 3 використанням концепції зворотних задач динаміки. Ця концепція передбачає формалізацію задачі здійснення заданої траєкторії руху при виникненні нештатної ситуації шляхом стабілізування програмного руху (термінальне керування, адаптивне стеження). Методика синтезу відновлювального керування 3 використанням концепції зворотних задач динаміки доцільно застосовувати для побудови систем керування дистанційно пілотованих літальних апаратів. Запропонований підхід застосовний як до одновимірних, так і багатовимірних систем автоматичного керування.

\section{Література}

1 Барбашин Е.А. О приближенном осуществлении движения по заданной траектории, Автомат. и телемех., 1961, том 22, вып. 6. - с. 681-687.

2 Петров Б. Н., Крутько П. Д. Построение алгоритмов управления как обратная задача динамики, Докл. АН СССР, 1979, том 247, №5. - с. 1078-1081.

3 Петров Б.Н., Крутько П.Д. Обратные задачи динамики управляемых систем. Линейные модели. М., Техническая кибернетика, №4, 1980. - с. 147-156.

4 Петров Б. Н., Крутько П. Д. Обратные задачи динамики управляемых систем. Нелинейные модели. М., Техническая кибернетика, №5, 1980. - с. 149-167.

5 Петров Б. Н., Крутько П. Д. Конструирование алгоритмов управления полетом на основе решения обратных задачи динамики. Продольное движение. М., Техническая кібернетика, №2, 1981 - c. $162-170$.

6 Галиуллин А. С. Методы решения обратных задач динамики. М.: Наука, 1986. - 224 с.

7 Артюшин Л.М., Панов В. И., Шамов Г. В. Синтез алгоритмов управления полетом на основе решения обратных задач динамики. Киев : КВВАИУ, 1982. - 44 с.

8 Артюшин Л.М. Синтез алгоритмов управления движением сложных механических систем по методу обратных задач динамики. Докл. АН УССР. Кибернетика и вычислительная техника, 1986, №8. - c. 73-76.

9 Trysnyuk V., Trysnyuk T., Okhariev V., Shumeiko V., Nikitin A. Cartographic Models of Dniester River Basin Probable Flooding // Scientific Bulletin Series D : Mining, Mineral Processing, Non-Ferrous Metallurgy, Geology and Environmental Engineering; Baia Mare - Vol. XXXII, No. 1 2018. - pp. 51-55.

10 Trofymchuk O., Trysnyuk V., Novokhatska N., Radchuk I. Geo-Information Technologies for Decision Issues of Municipal Solid Waste // Journal of Environmental Science and Engineering A3 (2014) - pp. 183-187.

11 Артюшин Л. М., Машков О. А., Дурняк Б. В., Сивов М. С. Теорія автоматичного керування. Львів, Вид. УАД, 2004. - 272 с.

12 Машков О. А. Синтез многомерных автоматических систем на основе решения обратных задач динамики. Киев.: КВВАИУ, 1989. - 76 с. 
O. Mashkov', V. Trysnyuk', Y. Mamchur ${ }^{2}$, S. Zhukauskas ${ }^{2}$, S. Nihorodova ${ }^{2}$, A. Kurylo ${ }^{2}$

${ }^{1}$ State Ecology Academy of Postgraduate Education and Management, Kyiv;

${ }^{2}$ Institute of Telecommunications and

Global Information Space

National Academy of Sciences

of Ukraine, Kyiv

\section{NEW APPROACH TO THE SYNTHESIS OF RECOVERING CONTROL FOR THE REMOTELY CONTROLLED AIRCRAFTS FOR ENVIRONMENTAL MONITORING}

The complication of control objects has resulted in the appearance of many problems, in which first the desired law of changes in the controlled process (program motion) should be calculated, and then the control law should be developed that ensures the exact or approximate implementation of this process in case of possible occurrence of emergency situations.

A new approach to the synthesis of recovering control for the remotely controlled aircrafts for environmental monitoring has been proposed. The possibility of using the concept of inverse dynamics problems to synthesize the control systems of remotely controlled aircrafts for stabilization on the guided path in stochastic setting has been substantiated. The main task is to develop the control system of program motion, which ensures the execution of the program trajectory with the specified accuracy in the presence of various kinds of perturbations.

The authors have proposed to develop the synthesis algorithms of recovering control for remotely controlled aircrafts using the concept of inverse dynamics problems. This concept involves the formalization of guided path problem in case of emergency situation by means of stabilizing the program motion (terminal control, adaptive tracking). The efficiency of control algorithm of the remotely controlled aircrafts based on the solution of the inverse dynamics problem for a stochastic multidimensional automatic system has been evaluated for the model example.

It is expedient to use the methodology of synthesizing the recovering control using the concept of inverse dynamics problems in the development of control systems of remotely controlled aircrafts. The proposed approach can be applied to both one-dimensional and multidimensional systems of the automatic control of complex dynamic objects.

Keywords: inverse dynamics problem, transition process, program trajectory, control system, transition period, control quality, remotely controller aircraft.

\section{References}

1 Barbashyn E. A. O pryblyzhennom osushchestvlenyy dvyzhenyia po zadannoi traektoryy, Avtomat. y telemekh., 1961, tom 22, vyp. 6. - c. 681-687.

2 Petrov B. N., Krutko P. D. Postroenye alhorytmov upravlenyia kak obratnaia zadacha dynamyky, Dokl. AN SSSR, 1979, tom 247, №5. - c. 1078-1081.

3 Petrov B.N., Krutko P.D. Obratnye zadachy dynamyky upravliaemykh system. Lyneinye modely. M., Tekhnycheskaia kybernetyka, №4, 1980. - s. 147-156.

4 Petrov B. N., Krutko P. D. Obratnye zadachy dynamyky upravliaemykh system. Nelyneinye modely. M., Tekhnycheskaia kybernetyka, №5, 1980. - s. 149-167.

5 Petrov B. N., Krutko P. D. Konstruyrovanye alhorytmov upravlenyia poletom na osnove reshenyia obratnykh zadachy dynamyky. Prodolnoe dvyzhenye. M., Tekhnycheskaia kibernetyka, №2, 1981 - s. 162-170.

6 Halyullyn A. S. Metody reshenyia obratnykh zadach dynamyky. M.: Nauka, 1986. - 224 s.

7 Artiushyn L.M., Panov V. Y., Shamov H. V. Syntez alhorytmov upravlenyia poletom na osnove reshenyia obratnykh zadach dynamyky. Kyev : KVVAYU, 1982. - 44 s.

8 Artiushyn L.M. Syntez alhorytmov upravlenyia dvyzhenyem slozhnykh mekhanycheskykh system po metodu obratnykh zadach dynamyky. Dokl. AN USSR. Kybernetyka y vychyslytelnaia tekhnyka, 1986, №8. - s. 73-76.

9 Trysnyuk V., Trysnyuk T., Okhariev V., Shumeiko V., Nikitin A. Cartographic Models of Dniester River Basin Probable Flooding // Scientific Bulletin Series D : Mining, Mineral Processing, Non-Ferrous Metallurgy, Geology and Environmental Engineering; Baia Mare - Vol. XXXII, No. 1 2018. - pp. 51-55. 
10 Trofymchuk O., Trysnyuk V., Novokhatska N., Radchuk I. Geo-Information Technologies for Decision Issues of Municipal Solid Waste // Journal of Environmental Science and Engineering A3 (2014) - pp. 183-187.

11 Artiushyn L. M., Mashkov O. A., Durniak B. V., Syvov M. S. Teoriia avtomatychnoho keruvannia. Lviv, Vyd. UAD, 2004. - $272 \mathrm{c}$.

12 Mashkov O. A. Syntez mnohomernykh avtomatycheskykh system na osnove reshenyia obratnykh zadach dynamyky. Kyev.: KVVAYU, 1989. - $76 \mathrm{~s}$.

Надійшла до редакиії 17 травня 2019 р. 